\title{
EFFECT OF DEHYDROEPIANDROSTERONE ON LIPEMIA, GLUCOSE TOLERANCE, INSULINEMIA, INSULIN BINDING TO ERYTHROCYTES IN SHR/N-CP LEAN RATS OF KOLETSKY TYPE
}

\author{
Věroslav Golda, Jiřina Hilgertová* \\ Institute of Experimental Neurosurgery, University Teaching Hospital, Hradec Králové; \\ (Head: doc. MUDr. J. Náhlovský, CSc.) \\ *Laboratory for Endocrinology and Metabolism, The first Faculty of Medicine of Charles University, Prague; \\ (Head: prof. MUDr. V. Schreiber, DrSc.)
}

\begin{abstract}
Summary: Experiments were performed in the genetically hypertensive lean males of Koletsky type.It was monitored the effect of dehydroepiandrosterone (DHEA) treatment on lipemia, glucose tolerance, insulinemia, insulin binding to erythrocytes, fat pads, body weight and pellet intake. DHEA was applied in two doses: 10 and $20 \mathrm{mg}$ per $\mathrm{kg}$ b.w.,i.p.,for $11 \mathrm{days}$ when glucose tolerance was monitored and for 21 days when the remaining parameters were analyzed. DHEA shows dose dependent decrease in changes of body weight over injection period, in plasma triglycerides and total plasma cholesterol, decrease being most expressed under the higher dose. High as well low of DHEA decreases the sum of glycaemia obtained 30, 60, 120 and 180 min after glucose loading (area under the curve) i.e., DHEA alleviates genetically based glucose intolerance. DHEA induced hypophagia under the higher dose treatment. Insulin binding to erythrocytes was not influenced by DHEA.
\end{abstract}

Key words: SHR of Koletsky type; Triglycerides; Cholesterol; Glucose tolerance; Insulinemia; Insulin binding to erythrocytes; Pellet intake; Dehydroepiandrosterone

\section{Introduction}

In our previous study (10) we documented that the alleviation of glucose intolerance in SHR-cp lean males by the long lasting terguride treament is accompanied not only by decrease of insulinemia, but by the increase of insulin binding to erythrocytes as well. Thus the possible causal relationship between increase of insulin binding, the decrease of insulinemia and alleviation of glucose intolerance in the SHR-cp lean males can be taken into consideration. But the findings of Nestler et al (17) do not exclude that the above mentioned changes in insulin binding,insulinemia and in glucose tolerance can be considered only as coincidence without causal relationship or that there are more regulative mechanism of glucose tolerance. The mentioned authors claimed that in neither their study of young nonobese (16) nor obese men $(17,21)$ did DHEA administration affect either fasting serum insulin or glucose levels or tissue sensitivity to insulin (as determined by either the hyperinsulinemic-euglycemic clamp technique (5)or Bergman's modified minimal model technique (1), respectively). Nevertheless, they found DHEA's beneficial action on glucose tolerance. Coleman et al.(7) found that DHEA is potent to prevent the development of diabetes in genetically diabetic $(\mathrm{db} / \mathrm{db})$ mice. Moreover, they found (7) that
DHEA improved glucose tolerance and reduced plasma insulin in old normal BL/6 female mice. The mentined DHEA effect the authors (7) explained by increase of sensitivity to insulin.

Thus it is well founded to verify the effect of DHEA long lasting treatment in the SHR/N-cp lean rats.

\section{Material and methods}

\section{Animals}

Experiments were carried out in lean genetically hypertensive males of Koletsky type(controls: $n=7$,low dose of DHEA:n=9, high dose of DHEA:n=11). Lean SHR/N-cp rats represents dominant non-obese homozygotes and heterozygotes whereas their obese siblings are recessive homozygotes (cp-cp). The abnormal animals were obtained by Koletsky(12) when mating a female spontaneiously hypertensive rat (Okamoto -Aoki strain) with normotensive Sprague-Dawley male rat. The genetically obese animals appeared after several generations of selective inbreeding of hypertensive offsprings of the original cross.

After weaning at the age of 30 days the animals were kept in group of four and supplied with water and DOS$2 \mathrm{~b}$ pelleted diet ad libitum. During the experiment the animals were kept in group of two in PVC boxes (humidity: 
$55+10 \%$, room temperature: $22+1{ }^{\circ} \mathrm{C}$, natural lighting). Body weight,water and pellet intake was daily controlled (except weekends).

\section{Dehydoepiandrosterone (DHEA) treatment}

The drug was appliedd i.p. at the dose 10 and $20 \mathrm{mg}$ per $\mathrm{kg}$ b.w. for 21 days (when lipemia, insulinemia, insulin binding to erythrocytes, body fat pads and percentage changes of body weight over injection period was investigated) or for 11 days (when glucose tolerance was monitored).DHEA was dissolved in aqua pro inj. (10 or $20 \mathrm{mg}$ in $1 \mathrm{ml}$ ), solution was applied $0.1 \mathrm{ml} / 100 \mathrm{~g}$ b.w.In control animals aqua pro inj. $0.1 \mathrm{ml} / 100 \mathrm{~g}$ b.w. was applied i.p. DHEA was obtained from Web Advanced Products, Inc., Woodd Cross, UT, USA.

\section{Insulin binding to rat erythrocytes}

Plasma was separated from approximately $3 \mathrm{ml}$ of heparinized blood drawn by cardiac puncture(under ether anaesthesia by open chest). Erythrocytes were obtained in the presence of constant amount of ${ }^{125} \mathrm{I}(\mathrm{A}-14)$ insulin $(33 \mathrm{pM})$ at $15^{\circ} \mathrm{C} 3$ hours. Results were corrected for nonspecific binding. The details of the method are published previously (Hilgertová et al.(1990).

\section{Plasma lipids and insulinemia.}

Blood sampled by cardiac puncture (under light ether anaesthesia at 07.00 a.m. after $14 \mathrm{~h}$ starvation) was centrifuged and the serum stored in plastic tubes at $-2 \mathrm{O}^{\circ} \mathrm{C}$.Total plasma cholesterol and plasma triglycerides were estimated enzymatically by Hitachi analyzer,plasma insulin was estimeted by RIA.

\section{Glucose tolerance}

Blood was sampled to heparinized capillaries (from the retrobulbar plexus under light ether anaesthesia) before glucose loading (basal glycaemia) as well as $30,60,120$ and 180 min after glucose loading. Glucose $(3 \mathrm{~g} / \mathrm{kg}$ b.w., $30 \%$ solution) was applied intragastrically after $14 \mathrm{~h}$ starvation. Glycaemia was estimated enzymatically.

\section{Fad pads}

Immediately after finishing the cardial puncture the animal was decapitated, epididymal and retroperitoneal fat pads were weighted and their weight expressed in $\mathrm{g} / 100 \mathrm{~g}$ b.w.

\section{Statistics}

The data were analyzed by program SOLO. Statistical significance of intergroup differences was evaluated by t-test.

\section{Results}

\section{Effect of DHEA on \% of changes of body weight (Table l)}

When compared to controls, low dose shows no effect, high dose shows profound decrease. Effect of low dose and high dose differs significantly.
Effect of DHEA on fat pads (Table l)

DHEA shows no effect on epididymal and/or retroperitoneal fat pads.

Table l:

\begin{tabular}{|c|c|c|c|c|}
\hline Group & $\begin{array}{c}\text { Initial } \\
\text { body } \\
\text { weight } \\
(\mathrm{g})\end{array}$ & $\begin{array}{c}\text { \% changes } \\
\text { of body } \\
\text { over } \\
\text { injection } \\
\text { period }\end{array}$ & $\begin{array}{c}\text { Epididymal } \\
\text { fat pad } \\
\text { (g/100g b.w. }) \\
\text { b.w. })\end{array}$ & $\begin{array}{c}\text { Retroperi- } \\
\text { toneal fat } \\
\text { pad }(\mathrm{g} / 100 \mathrm{~g}\end{array}$ \\
\hline Controls(7) & $289+16$ & $+7.00+2.89$ & $1.29+0.31$ & $1.25+0.28$ \\
\hline DHEA-10(9) & $268+21^{\mathrm{bB}}$ & $+7.00+3.88$ & $1.13+0.39$ & $1.05+0.39$ \\
\hline DHEA-20(11) & $288+26$ & $+1.91+2.59^{\mathrm{dD}}$ & $1.29+0.17$ & $1.33+0.33$ \\
\hline
\end{tabular}

Means + SEM are presented. The number of animals per group is in the brackets. The significance of values (by two tailed t-test) refers to the comparison between control and dehydroepiadrosteron treated animals. Abbreviations: DHEA-10: $10 \mathrm{mg} / \mathrm{kg}$ b.w., DHEA-20: $20 \mathrm{mg} / \mathrm{kg}$ b.w., a $\mathrm{P}<0.10, \mathrm{~b}-\mathrm{P}<0.05, \mathrm{c}-\mathrm{P}<0.02, \mathrm{~d}-\mathrm{P}<0.01$ (significance versus controls). Capital:significance DHEA-10 versus DHEA-20.

\section{Effect of DHEA on plasma triglycerides and total plasma cholesterol (Table 2)}

DHEA shows dose dependent effect (i.e. decrease) on plasma triglycerides as well as on total plasma cholesterol.

In both cases high dose shows significantly greater effect. Low dose shows effect only on plasma triglycerides.

\section{Pellet intake (Table 2)}

Hypophagia was induced by the higher dose. Low dose remained without effect.

\section{Table 2:}

\begin{tabular}{|c|c|c|c|}
\hline Group & $\begin{array}{c}\text { Plasma } \\
\text { triglyce- } \\
\text { rides } \\
(\mathrm{mmol} / \mathrm{l})\end{array}$ & $\begin{array}{c}\text { Total plasma } \\
\text { cholesterol } \\
(\mathrm{mmol} / \mathrm{l})\end{array}$ & $\begin{array}{c}\text { Pellet intake } \\
(\mathrm{g} / 100 \mathrm{~g} \text { b.w./day }\end{array}$ \\
\hline Controls(7) & $0.90+0.15$ & $1.80+0.16$ & $7.77+0.78$ \\
\hline DHEA-10(9) & $0.67+0.08^{\mathrm{d}}$ & $1.78+0.10$ & $7.19+0.65$ \\
\hline DHEA-20(11) & $0.53+0.09^{\mathrm{dD}}$ & $1.56+0.12^{\mathrm{D}}$ & $6.93+0.58^{\mathrm{d}}$ \\
\hline
\end{tabular}

Means + SEM are presented. The abbreviations are the same as in Table 1.

\section{Basal glycaemia (Table 3)}

Under the high as well as low dose there is a decrease.

\section{Glucose tolerance (Table 3)}

High as well as low dose decrease the sum of glycaemia obtained 30,60,120 and $180 \mathrm{~min}$ after glucose loading (area under the curve). 


\section{Insulinemia (Table 3)}

Insulinemia shows no changes after long lasting DHEA treatment.

Percentage of insulin binding to erythrocytes (Table 3)

Insulin binding was not influenced by long lasting DHEA treatment.

Table 3:

\begin{tabular}{|c|c|c|c|c|}
\hline Group & $\begin{array}{c}\text { Basal gly- } \\
\text { caemia } \\
(\mathrm{mmol} / \mathrm{l})\end{array}$ & $\begin{array}{c}\text { Glucose tole- } \\
\text { rance-" area } \\
\text { under the } \\
\text { curve“ } \\
(\mathrm{mmol} / \mathrm{l})\end{array}$ & $\begin{array}{c}\text { IRI } \\
(\mathrm{pmol} / \mathrm{l})\end{array}$ & $\begin{array}{c}\text { \% insulin } \\
\text { binding to } \\
\text { erythrocy- } \\
\text { tes }\end{array}$ \\
\hline Controls(7) & $5.45+0.61$ & $29.32+2.13$ & $243+77$ & $2.05+0.92$ \\
\hline DHEA-10(9) & $4.46+0.44^{\mathrm{d}}$ & $24.04+2.71^{\mathrm{d}}$ & $222+38$ & $2.24+0.88$ \\
\hline DHEA-20(11) & $4.18+0.44^{\mathrm{d}}$ & $25.85+3.37^{\mathrm{c}}$ & $206+103$ & $1.64+0.67(9)$ \\
\hline
\end{tabular}

Mean + SEM are presented. The abbreviations are the same as in Table 1."Area under the curve" represents the sum of glycaemia $30,60,120$ and $180 \mathrm{~min}$ after glucose loading.

\section{Discussion}

As mentioned in the introduction in our previous paper (10) we documented in SHR/N-cp lean males that long lasting terguride treatment shows alleviation of glucose intolerance. This is accompanied by decrease of insulinemia and by increase of percentage of specific insulin binding to erythrocytes. Our recent data documented that the changes in glucose tolerance is not in all cases accompanied by parallel changes in insulinemia and in insulin binding.

At this place it would be suitable to mention the data obtained by Škrha et al. (20). They monitored the effect of short term fasting in obese type 2 diabetes mellitus. Short term fasting reduced slightly but significantly body weight, which was accompanied by reduction of fasting plasma glucose, by increased glucose disposal rate and by increase of metabolic clearance rate of glucose. No changes of insulin receptors on erythrocytes were observed.

There are two common features with our results, i.e., the beneficial effect of treatment of the abnormalities in glucose metabolism in the mentioned type of patients is not accompanied by the changes in insuline receptors on erythrocytes but there is decrease of fasting plasma glucose. The mentioned results(20) suggest that elevated insulin sensitivity has not to be accompanied by changes in insulin receptors on erythrocytes.

Svačina et al. (18) nowdays when studying the relationship between the the basal level of DHEA and insulin sensitivity they found that there is significant positive correlation between the mentioned parameters. They studied the changes of plasmatic DHEA during IVGTT in health subject and in patients suffering from diabetes mellitus. The increase of insulin was followed by elevation of DHEA. They estimated tissue sensitivity to insulin by hyperinsulinemic-euglycaemic clamp technique.These data suggest a close relationship between insulinemia induced by IVGTT and DHEA. Direct pendant to our measurement is presented by Nestler at al.(16,17)and by Coleman et al $(6,7)$.Nestler et al. $(16,17)$ found that in young obese as well as nonobese men DHEA shows no changes in tissue sensitivity to insulin (as determined by hyperinsulinemic-euclycaemic clamp technique), but that DHEA shows beneficial effect on glucose tolerance. Coleman et al. (6) demonstrated that DHEA addministration prevented the development of diabetes mellitus in genetically diabetic $(\mathrm{db} / \mathrm{db})$ or obese (ob/ob) mice. In the other paper Coleman et al. (7) showed that DHEA increases tissue sensitivity to insulin in aged normal mice. As the markers of the elevation of tissue sensitivity to insulin they judged the improved glucose tolerance and reduced plasma insulin The mentioned beneficial effect of DHEA can be in our experiments expressed by decrease of basal glycaemia and by the decrease of ,area under the curve", i.e. by the decrease of sum of glycaemia $30,60,120$ and 180 min after glucose loading. Both changes can be viewed as an expression of elevation of insulin sensitivity. But it remains to be solved why this assumed change in insulin sensitivity is not accompanied by the changes in insulin binding to erythrocytes and by some changes in insulinemia.

This question arises when we consider the effect of terguride on the glucose tolerance in the animals of the same strain and sex, i.e., SHR/N-cp lean. We found that the decrease of glucose tolerance was accompanied by elevation of insulin binding to erythrocytes and by decrease by insulinemia (10).

It cannot be a priori excluded that the same changes in the glucose tolerance induced by two different substances (terguride versus DHEA) are based on the changes of insulin sensitivity (i.e., its elevation), but this assumed increase of insulin sensitivity is not accompanied in the same manner by changes in insulin binding to erythrocytes and by the changes in insulinemia. Similarly, while the glucose intolerance which we found in SHR/N-cp obese rats as well as in their lean siblings (9) is accompanied by profoundly reduced specific insulin binding on erythrocytes (11), then glucose intolerance induced by brain oligemic hypoxia shows no changes in insulin binding to erythrocytes (in preparation).

On the other hand, glucose intolerance induced by oligemic brain hypoxia is accompanied by hyperinsulinemia. All the mentioned data suggest that glucose intolerance is conditioned by decrease of insulin sensitivity, but its expression in the changes of insulin binding to erythrocytes and the changes in insulinemia can be dependent on the factor which evoked the glucose intolerance (genetic factor versus brain oligemic hypoxia) and/or on factor alleviating glucose intolerance (terguride versus DHEA). 
It is known (19) that under the conditions of insuficiency of insulin secretion (diabetes I) or when insulin resistence was developed (diabtes II), triglycerides are elevated by the intensified lipolysis and by increase input of nonestirified acids to the liver. DHEA in our series of experiments decreases the basal glycaemia and increase glucose tolerance (Table 3).Considering the last mentioned DHEA effect as an expression of increase of insulin sensitivity, then decrease of triglycerides induced by DHEA (Table 2) can be judged as a consequence of the changes of the mentioned insulin sensitivity (i.e., its elevation). As mentioned above, the effect of DHEA is not limited only to changes in glucose tolerance. We documented dose dependent effect on plasma triglycerides and total plasma cholesterol.

While decrease of cholesterol was found only after higher dose, then decrease of plasma triglycerides was found under low as well as high dose (Table 2). Moreover, the decrease after high dose was significantly higher than after low dose.

As to the effect of DHEA on plasma triglycerides our data are in accordance with Mohan et al. (14). They found in rat that treatment with DHEA lowered triglyceride levels regardless of whether it was elevated by diet or not. On the other hand, total plasma cholesterol levels were lowered by DHEA only when it was higher than normal due to feeding the condensed milk diet (14). Kurzman et al. (13) found that DHEA is potent to lower total plasma cholesterol in both lean and obese dogs. Moreover, studies $(8,16)$ using human subjects have shown decrease in low density lipoprotein cholesterol levels following DHEA treatment.

At this place the nutrition parameters of our rats must be mentioned. We demonstrated (Table 2) dose dependent effect of DHEA on pellet intake. While the low dose remained without effect, then the higher dose induced hypophagia.

It cannot be excluded that the decrease of triglycerides as well as cholesterol are done to a certain degree by hypophagia.It does not hold good for triglycerides under the lower dose of DHEA. There was not proved statistically significant decrease of pellet intake.

With the same precaution we must take the lowering effect of DHEA in basal glycaemia and in percentage of changes of body weight over injection period. Especially under the higher dose the effect of DHEA induced hypophagia cannot be overlooked.

As to the effect of DHEA on food intake per se there is no uniformity in the published data. On one side, Cleary et al $(2,3)$ when studying the effect of DHEA in obese Zucker rat, they found that cumulative food intakes tended to be lower in obese-treated compared with obese-nontreated rats. On the other hand, Cleary (4) documented that DHEA in Sprague-Dawley rats DHEA does not show any effect on nutrition.

It is obvious that when we want to study hypolipidemic effect of DHEA then species, genetic, and nutritional factors must be taken into consideration.

\section{Conclusions}

Data presented by Nestler et al. $(16,17)$, Svačina et al. (18), Škrha et al. (20) as well as our previous data (10) and recent findings suggest that DHEA can be potent to influence insulin sensitivity but that this influence is not expressed in all cases by change in insulin binding to erythrocytes and by the changes in insulinemia.Moreover, DHEA can show species dependent effect in the influence on insulin sensitivity.

\section{Acknowledgement}

This paper was supported by Internal Grant Agency of Ministry of Health of the Czech Republic No 3684-3. The authors wish to thank Carl T. Hansen, Animal Genetics Division, National Institute of Health, Bethesda, USA,for providing the genetically hypertensive rats of Koletsky type.

\section{References}

1. Berdanier CD, McIntosh MK. Further studies on the effects of dehydroepiandrosterone on hepatic metabolism in BHE rats. Proc Soc Exp Biol Med 1989;192:242-7.

2. Cleary MP, Shepherd A, Jenks B. Effect of dehydroepiandrosteron in lean and obese Zucker rats. J Nutr 1984;114:1242-51.

3. Cleary MP, Fox N, Lazin B, Billheimer JT. A comparison of the effects of dehydroepiandrosterone treatment to ad libitum and pair-feeding in the obese Zucker rat. Nutr Res 1985;5:1247-57.

4. Cleary MP, Shepherd A, Zisk J., Schwartz AG. Effect of dehydroepiandrosterone on body weight and food intake in rats. Nutr Behav 1983;1:127-36.

5. Cleary MP, Hood SS, Chando C, Hanson CT, Billheimer JT. Response of sucrose-fed BHE-rats to dehydroepiandrosterone. Nutr Res 1984;4:485-94.

6. Coleman DL, Leiter EH, Schwitzer RW. Therapeutic effects of dehydroepiandrosterone (DHEA) in diabetic mice.Diabetes 1982;31:830-3.

7. Coleman DL, Schwitzer RW, Leiter EH. Effect of genetic background on the threrapeutic effects of dehydroepiandrosterone (DHEA) in diabetes-obesity mutans and in aged normal mice. Diabetes 1984;33:26-32.

8. Fassati P, Fessati M, Šonka J, Josifko M. Treatment of stabilized liver cirrhosis by dehydroepiandrosterone sulphate. Agressologie 1973;14:259-68.

9. Golda V, Cvak L. Terguride but not bromocriptine alleviatted glucose tolerance abnormalities and hyperlipidemia in obese and lean genetically hypertensive Koletsky rats. Physiol Res 1994;43:299-305.

10. Golda V, Hilgertová J. Effect of tran-dihydro-lisuride on insulin binding, insulinemia, glucose tolerance and cholesterolemia in SHR Koletsky rats. Physiol Res (in press).

11. Hilgertová J, Kummel L, Hovorka R, Golda V. Decreased insulin binding and internalization in hepatocy- 
tes and erythrocytes of SHR Koletsky rats depend on the presence of „f“ gene and on sex. Metabolic characteristics of hepatocytes from obese rats. In: Klimeš I, Howard BV, Kahn CR, eds. Insulin and cell membrane. New York:Harwood Academic Publishers, 1990:81-92.

12. Koletsky S. Pathologic findings and laboratory data in a new strain of hypertensive rats. Am J Pathol 1975;80:12940.

13. Kurzman ID, MacEven EG, Haffa ALM. Reduction in body weight and cholesterol in spontaneously obese dogs by dehydroepiandrosterone. Int J Obes 1990;14:95-104.

14. Mohan PF, Ihnen JS, Levin BE, Cleary MP. Effects of dehydroepiandrosterone treatment in rats with diet-induced obesity. J Nutr 1990;120:1103-14.

15. Muller S, Cleary MP. Glucose metabolism in isolated fat cells from lean and obese Zucker rats following treatment with dehydroepiandrosterone. Metabolism 1985; 34:278-84.

16. Nestler JE, Barlascini CO, Clore JN, Blackard WG. Dehydroepiandrosterone reduces serum low density lipoprotein levels and body fat but does not alter insulin sensitivity in normal men. $\mathbf{J}$ Clin Endocrinol Metab 1988;66:57-61.
17. Nestler JE, John N, Blackard C, Blackard WG. Metabolism and actions of dehydroepiandrosteone in humans. J Steroid Biochem Molec Biol 1991;40:599-605.

18. Svačina Š, Kvapil M, Haas T, Šonka J. Insulin, steroids and steroidogenese. Česk Fyziol 1997;46:51-6.

19. Škrha J. Insulin resistance and non-insulin-dependent diabetes mellitus. Vnitr Lek 1994;41:105-9.

20.Škrha J, Šindelka G, Hilgertová J. The effect of dietary regimen and vitamin $\mathrm{E}$ on insulin action in obese type $2 \mathrm{di}$ abetes mellitus. Abstract of 3rd International Smolenice Insulin Symposium on Lipids and Syndrome of Insulin Resistance, August 28-September 1996, p.74.

21. Usiskin KS, Butterworth S, Clore JN et al. Lack of effect of dehydroepiandrosterone in obese man. Int J Obesity 1990; 14:457-63.

Submitted May 1997.

Accepted June 1997.

Doc. MUDr. PhDr. Věroslav Golda, CSc.,
Institute of Experimental Neurosurgery,
University Teaching Hospital, 50005 Hradec Králové, Czech Republic. 